Journal of Mechanical Engineering and Sciences (JMES)

ISSN (Print): 2289-4659; e-ISSN: 2231-8380; Volume 2, pp. 172-180, June 2012

(C) Universiti Malaysia Pahang, Pekan, Pahang, Malaysia

DOI: http://dx.doi.org/10.15282/jmes.2.2012.4.0015

\title{
CHARACTERISATION OF SPOT WELD GROWTH ON DISSIMILAR JOINTS WITH DIFFERENT THICKNESSES
}

\author{
Nachimani Charde \\ Department of Mechanical, Material and Manufacturing Engineering, \\ Faculty of Engineering, \\ The University of Nottingham Malaysia Campus, \\ Jalan Broga, 43500 Semenyih, Selangor Darul Ehsan, Malaysia \\ Email: nachi.charde@nottingham.edu.my
}

\begin{abstract}
A sound weld from spot welding is what most manufacturers desire and prefer for mechanical assemblies in their systems. The robustness is mainly attributed to the joining mechanism of mechanical parts. This paper focuses on the effect of parametric changes for dissimilar joints using 304 austenitic stainless steel and carbon steel of two different thicknesses. A pneumatic-based spot welder was used to accomplish the entire welding process. The parameters varied during the experiments are the welding current and welding time, while the electrode pressing force and electrode tip size are kept constant. The welding process began from a poor weld and moved on to a better weld by increasing the process parameters. However, this study is limited to the basic parametric variation to find the optimum parametric setup for 1 and $2 \mathrm{~mm}$ base metals. The welded specimens are subjected to tensile, hardness and metallurgical tests to characterise the spot weld growth for both thicknesses.
\end{abstract}

Keywords: Dissimilar joints, Different thicknesses, Carbon and Stainless Steel.

\section{INTRODUCTION}

Currently, in manufacturing industry, one mechanical assembly out of five is welded using resistance spot welding technology; for example, the automotive industry uses this technology for its body assemblies. The spot weld growths occur mainly due to the basic controlling parameters, such as current, welding time, electrode force and electrode tips (Maa, Chena, Bhole, Boudreau, Lee, \& Biro, 2008). The metal sheets are usually placed on top of the static lower electrode tip of the spot welder and the sheets pressed firmly together, using the upper electrode lever to reduce the contact resistance between the sheet-to-sheet and sheet-to-electrode, or vice versa (Dursun \& Zyurek, 2008). The firmly held base metals are then supplied with a huge current by which the contact area will be melted and form a joint between the metal sheets (Sun, Lang, Sun, $\& \mathrm{Li}, 2007)$. In order to accomplish this process, an adequate current, weld time, electrode force and a reasonable resistance across the base metals must be supplied, because heat develops in accordance with resistive changes $\left(Q=I^{2} R t\right)$. This study identifies the sufficient current and weld time when using a constant force and tip diameter. Other factors, such as corrosion due to coating removal, electrical resistance of base metals due to heat treatment, thermal conductivity of dissimilar materials, heat imbalance due to same tip size for dissimilar materials, gaps between sheet-to-sheet or sheet-to-electrodes also affect weld quality. However, the level of their effect is extremely small and can be treated as negligible (Yang, Zhang, Lai \& Chen, 2008). The 
objective of this paper is the characterisation of spot weld growth on dissimilar joints with different thicknesses.

\section{EXPERIMENTATION}

\section{Specimen Sizing, Material Properties and Weld Schedules}

The carbon and stainless steel test samples are of equal size $(200 \times 25 \mathrm{~mm})$ except for their thicknesses (1 and $2 \mathrm{~mm})$. A pair of water-cooled copper electrodes with tip diameters of $5 \mathrm{~mm}$ was used to join these base metals using a Japanese made JPC $75 \mathrm{kVA}$ spot welder. Figure 1 shows the specimen's dimension and alignment. The material properties of carbon and 304 austenitic stainless steel are listed in Table 1. A weld schedule was initially developed to weld 90 samples and has been tabulated in Table 2. There were three levels of current increment (7,8 and $9 \mathrm{kA})$ and three levels of time increment $(10,15,20$ cycles) with a constant force of $3 \mathrm{kN}$ and constant electrode tip of $5 \mathrm{~mm}$. Thus, the weld lobe's minimal values are $7 \mathrm{kA}$ and 10 weld cycle and the maximum values are $9 \mathrm{kA}$ and 20 weld cycles. The three levels of combination create 45 pairs of samples in both $(1$ and $2 \mathrm{~mm})$ thicknesses. Five samples were developed in each weld schedule and their averages were calculated later.

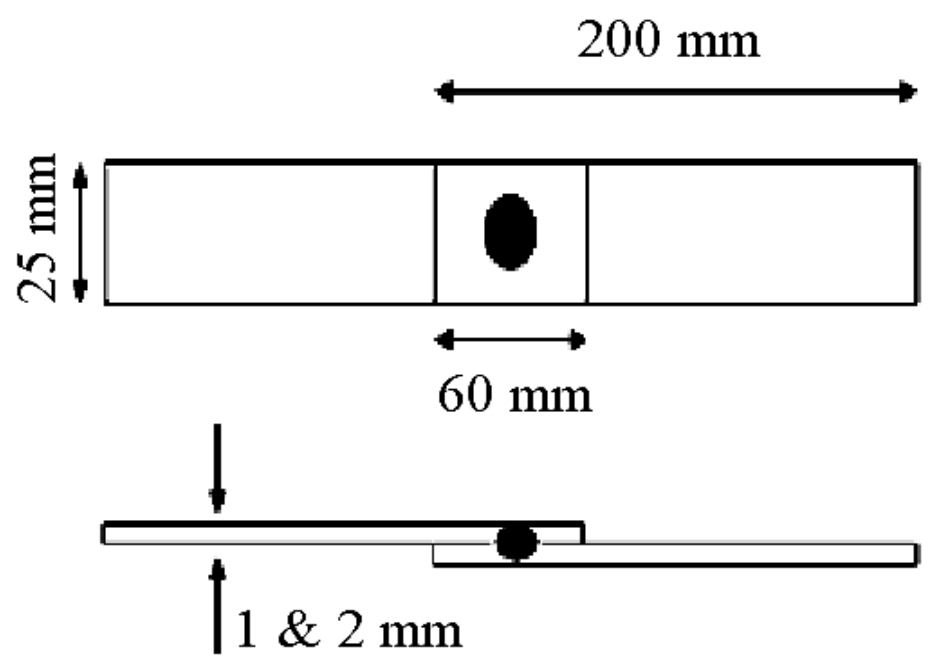

Figure 1. Test sample.

Table 1. Material properties .

\begin{tabular}{llcccccc}
\hline Element & $\mathrm{C}$ & $\mathrm{Cr}$ & $\mathrm{Ni}$ & $\mathrm{Mn}$ & $\mathrm{Si}$ & $\mathrm{S}$ & $\mathrm{P}$ \\
\hline \multicolumn{7}{c}{ 304 Austenitic Stainless Steel } \\
\hline 0.048 & 18.12 & 8.11 & 1.166 & 0.501 & 0.006 & 0.030 \\
\hline \multicolumn{7}{c}{ Carbon Steel } \\
\hline 0.25 & 0.90 & 0.006 & 0.050 & 0.040
\end{tabular}


Table 2. Weld schedule.

\begin{tabular}{cccccc}
\hline $\begin{array}{c}\text { Sample } \\
\text { No. }\end{array}$ & Material & $\begin{array}{c}\text { Electrode } \\
\text { Tip }(\mathrm{mm})\end{array}$ & $\begin{array}{c}\text { Current } \\
(\mathrm{kA})\end{array}$ & $\begin{array}{c}\text { Time } \\
(\text { cycle })\end{array}$ & $\begin{array}{c}\text { Force } \\
(\mathrm{kN})\end{array}$ \\
\hline $1-5$ & MS+SS & 5 & 7 & 10 & 3 \\
$6-10$ & MS+SS & 5 & 8 & 10 & 3 \\
$11-15$ & MS+SS & 5 & 9 & 10 & 3 \\
$16-20$ & MS+SS & 5 & 7 & 15 & 3 \\
$21-25$ & MS+SS & 5 & 8 & 15 & 3 \\
$26-30$ & MS+SS & 5 & 9 & 15 & 3 \\
$31-35$ & MS+SS & 5 & 7 & 20 & 3 \\
$36-40$ & MS+SS & 5 & 8 & 20 & 3 \\
$41-45$ & MS+SS & 5 & 9 & 20 & 3 \\
\hline MS = Carbon steel; SS = Stainless steel; MS+SS = Carbon steel + Stainless steel \\
\hline \multicolumn{5}{r}{}
\end{tabular}

\section{Tensile Test}

The tensile-shear test was carried out using a $100 \mathrm{kN}$ (max capacity) tensile testing machine to determine the strength of spot welded samples of both thicknesses. The crosshead speed was maintained at $50 \mathrm{~mm}$ per minute. The ultimate tensile strength (UTS) is shown in Figure 2, which is taken as the maximum weld strength when the weld fractured.

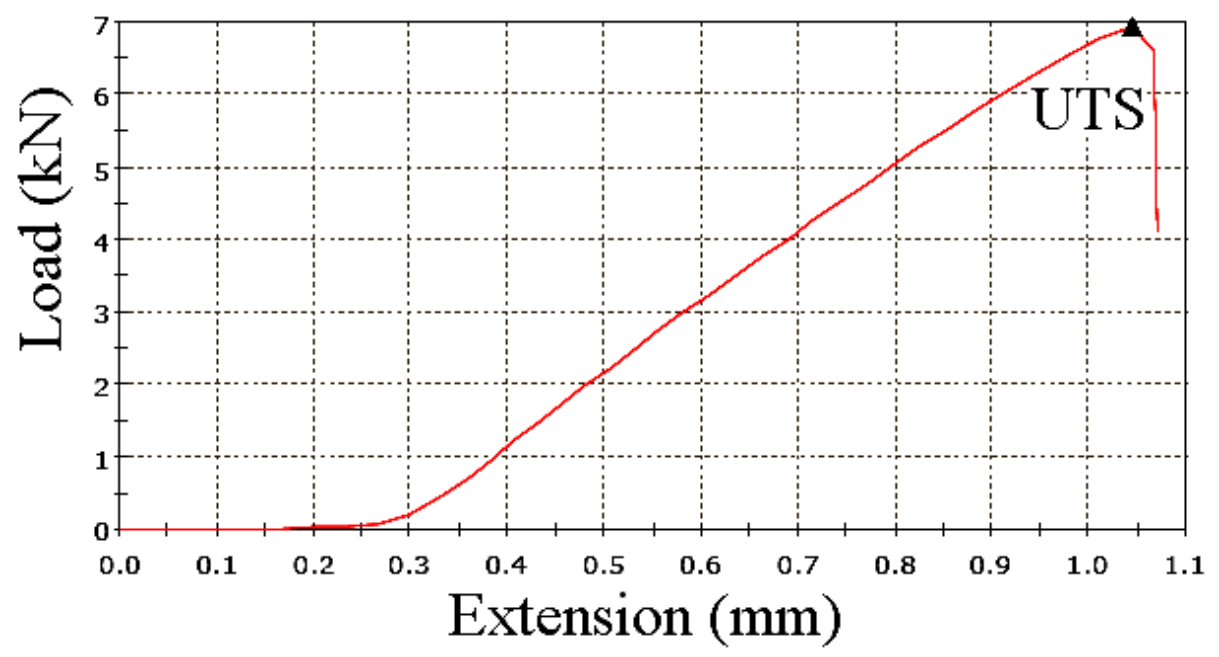

Figure 2. Tensile shear curve.

\section{Hardness Test}

The hardness test was conducted using a Rockwell hardness tester and the HRB scale. Figure 3 shows the hardness measured spots. The hardness was measured from the unwelded area through the heat affected zone and fusion zone and ended at the other side of base metals. It was conducted for both sides because one side was carbon steel and the other side was the stainless steel sheet. 


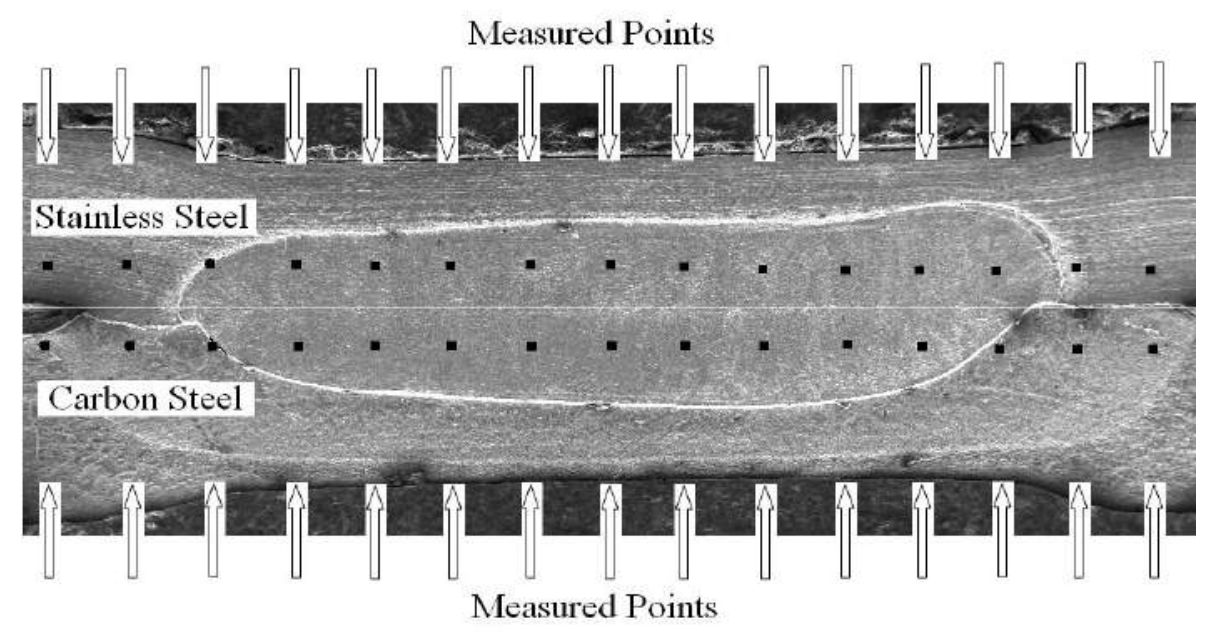

Figure 3. Hardness measured spots.

\section{Metallurgical Study}

Metallographic samples were produced using standard metallographic procedures. Optical microscopy was used to examine the macrostructures to measure the exact weld diameters of both the carbon (CS) and stainless steel (SS) sides. A typical macrostructure for carbon and stainless steel showing three distinct structural zones is shown in Figure 4.

a) Fusion zone (FZ) - zone that undergoes complete melting and solidification during weld cycle with a coarse grain. The width of the zone is equivalent to the weld nugget diameter.

b) Heat affected zone (HAZ) - zone that undergoes micro structural alteration during the weld cycle with grains that finer compared with the fusion zone.

c) Base metal (BM) - zone that is not affected during the weld cycle and the grain size remains the same.

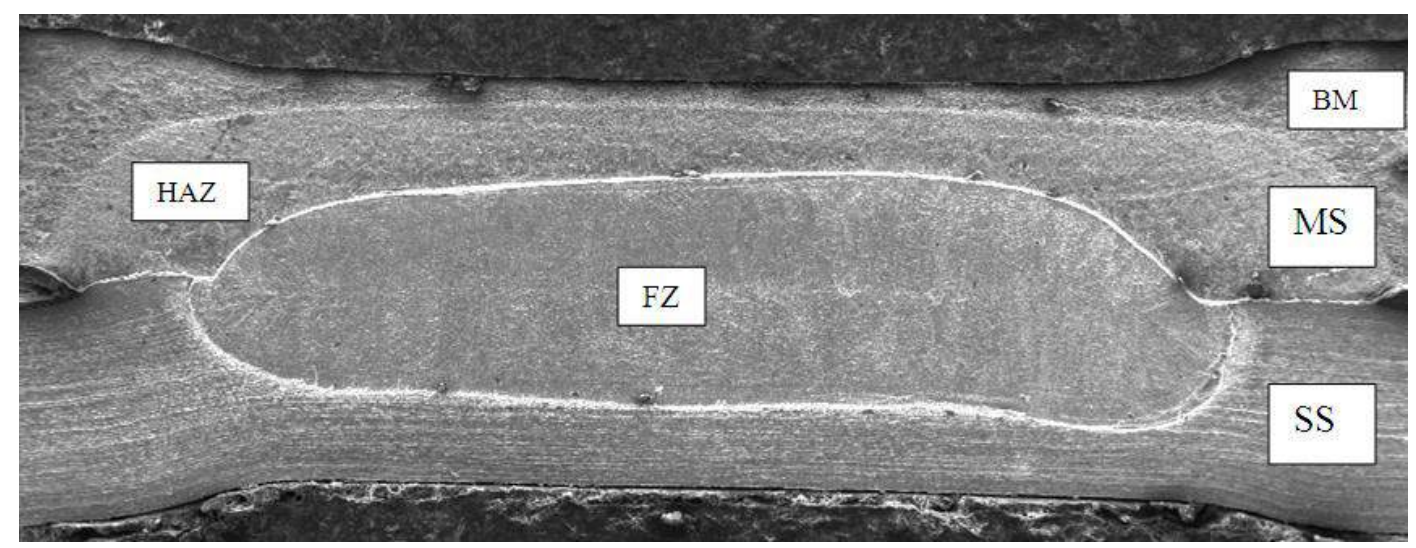

Figure 4. Structural zones. 


\section{RESULTS AND DISCUSSION}

Initially, the welded samples underwent hardness tests. The results show that the welded areas increased in hardness because of the heating action that occurred during the welding process. However, carbon steel is highly susceptible to heat treatment, whereas the stainless steels are not. However, the hardness of the fusion zone seems to be higher compared with that of both the heat affected zones and the base metals. Furthermore, the hardness on both sides of the joint appears to be almost same. Noticeably, the hardness increments or decrements were never once proportional in distribution as it fluctuated up and down. This was noticed during the welding and it has been shown in Figure 5 (Shamsul \& Hisyam, 2007).

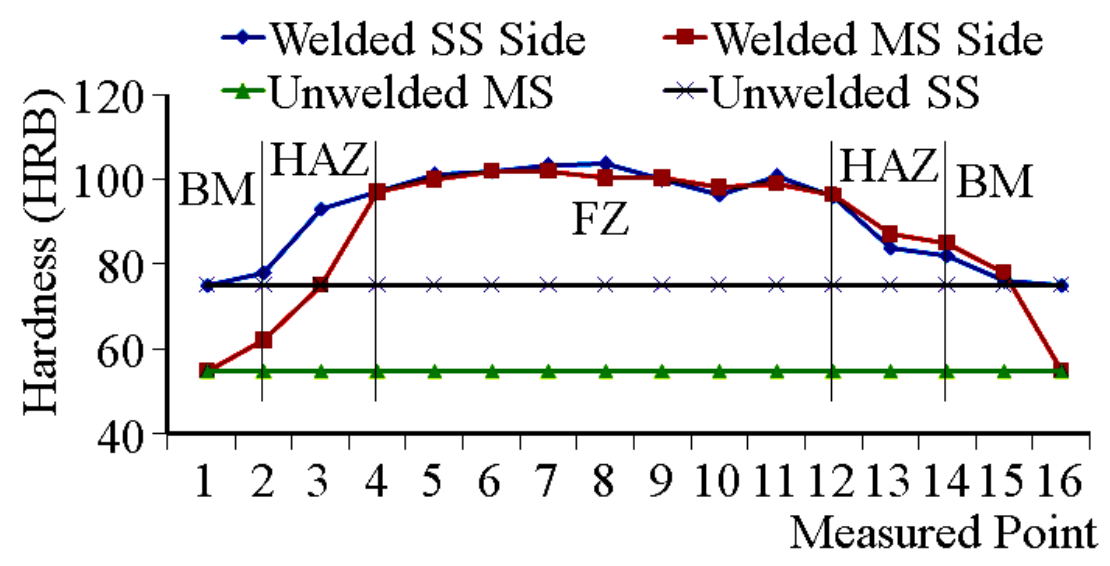

(a) $1 \mathrm{~mm}$ thickness

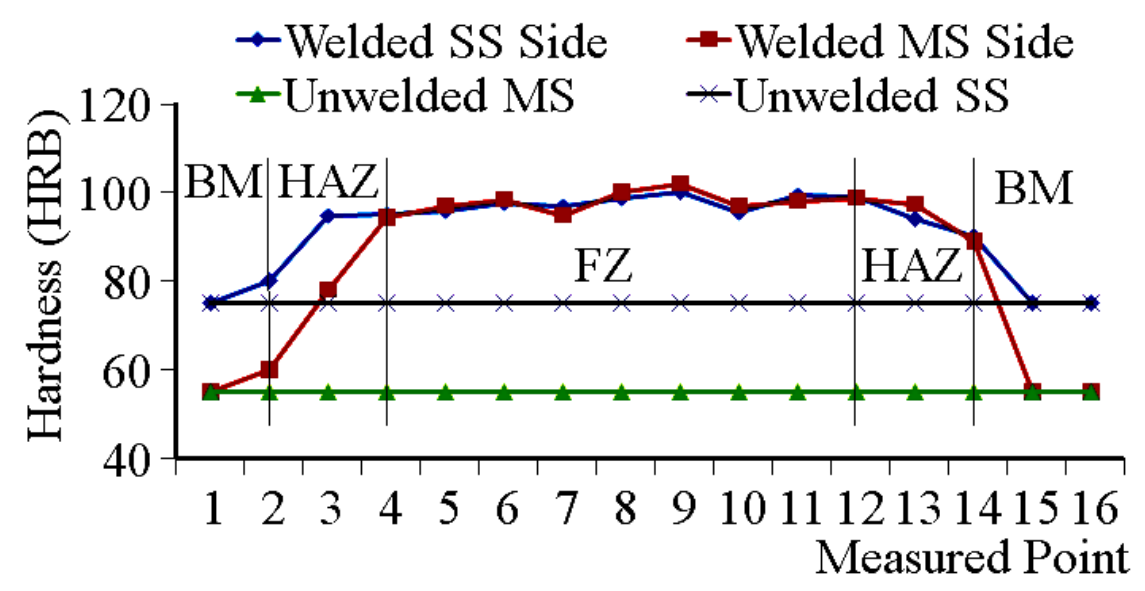

(b) $2 \mathrm{~mm}$ thickness

Figure 5. Hardness test.

Tensile tests were performed and the results are shown in Figure 6. A close relationship between the parametric variations and the previous study of von Maubeuge and Ehrenberg (2000) was revealed. When the current and weld time were increased with constant force and constant electrode tips, the tensile strength increased due to the strong bond of the metals sheets. For instance, the samples of both thicknesses ( 1 and 2 $\mathrm{mm}$ ) from weld schedule 1 and 2 show increments in strength due to current increments. Subsequently, the increase from schedule 2 to 3 also shows another further increment in 
strength (Kahraman, 2007). This happened because the current was increased from 6 to 7 and from 7 to $8 \mathrm{kA}$. Moreover, the weld time increment also shows similar results. For instance, when the weld time increment from weld schedule 1 to 4 and from 4 to 7 was considered, there were obvious increments in weld strength. This is also applicable to weld schedules 2, 5 and 8, and for weld schedules 3, 6, and 9. The first 3 weld schedules were done with 10 cycles and the following 3 with 15 and 20 cycles. As such, by increasing the weld cycles, sufficient time was given for the fusion to take place due to sufficient heat being supplied $\left(Q=I^{2} R t\right)$ to the welded areas (Kahraman, 2007). However, these experiments were not conducted for the extreme (expulsion) case. The tensile test result is presented in Figure 6.

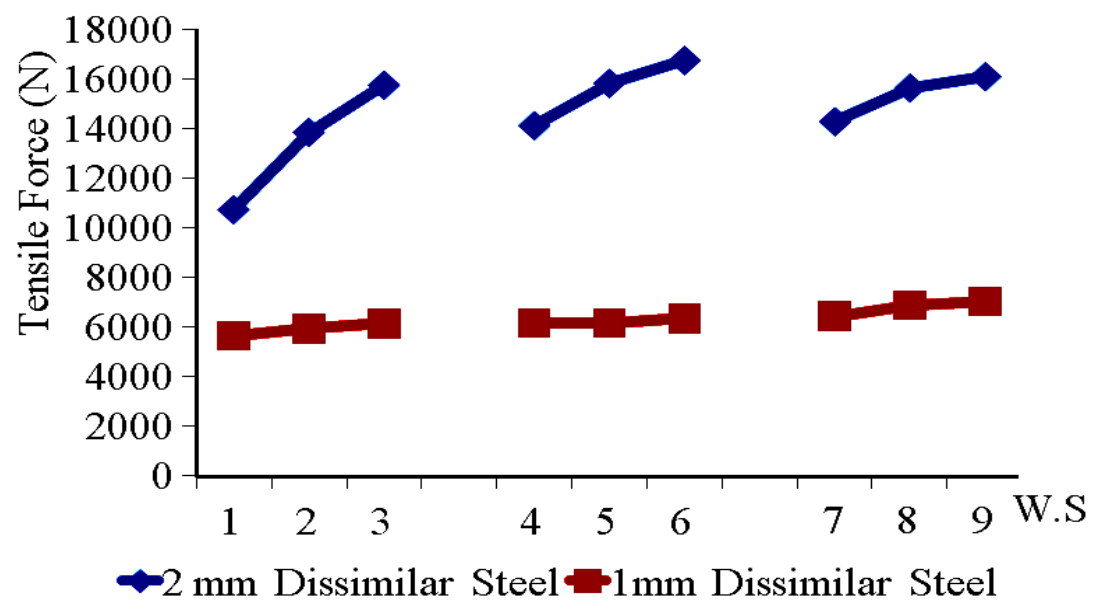

Figure 6. Tensile test.

A metallurgical study was conducted to analyse the relationship between the parametric variation and the diameter increments (Marashi, Pouranvari, Amirabdollahian, Abedi, \& Goodarzi, 2008). Twelve macrographs were included to visualise the similarity of the structural zones (base metal, fusion zone and heat affected zone) as well as the diameter increment. Figures 7 and 8 present macrographs of the current and weld time increment for 1 and $2 \mathrm{~mm}$ base metals, respectively. The thickness of the weld nuggets reduces as it becomes wider. However, the heat affected zones are clearly visible on carbon steel sides because of the inherent properties. It has been mentioned above that when the weld schedule from 1 to 2 shows an increment in strength due to the current increment, then diameter increments from 4.446 to $4.563 \mathrm{~mm}$ are also noticed in the macrographs. Furthermore, when weld schedule from 2 to 3 shows an increment in strength due to the current increment, diameter increments from 4.563 to $4.831 \mathrm{~mm}$ are also noticed. This is because the diameter increment caused a greater area to be united and form a better joint. Better joints require greater pulling forces to break the weld joints, as shown by the tensile tests (Qiua, Satonakab, \& Iwamotob, 2009). Similarly, the weld time increment from weld schedule 1 to 4 and 4 to 7 shows increments in strength with respect to diameter increments. The diameter increments were found to be 4.265 to $4.344 \mathrm{~mm}$ for weld schedules 1 to 4 and 4.344 to $4.446 \mathrm{~mm}$ for weld schedules 4 to 7 . It can be seen that the thicknesses do not alter the results when sufficient current and weld time are supplied (Cha \& $\mathrm{Na}, 2003$ ). These results are vary when poor weld nuggets. Table 3 lists the common material properties for carbon and stainless steel, which changes the flow rate of current during welding and causes the asymmetrical view of the welded areas. 
Table 3. Electrical and thermal properties.

\begin{tabular}{lcc}
\hline Properties & Stainless steel & Carbon steel \\
\hline Density & $8.00 \mathrm{~g} / \mathrm{cm}^{3}$ & $7.85 \mathrm{~g} / \mathrm{cm}^{3}$ \\
Melting Point & $1400-1450^{\circ} \mathrm{C}$ & $1426-1538^{\circ} \mathrm{C}$ \\
Electrical Resistivity & $6.89 \times 10^{-7} \Omega . \mathrm{m}$ & $1.611 \times 10^{-7} \Omega . \mathrm{m}$ \\
Thermal Conductivity & $16.2 \mathrm{~W} / \mathrm{m} . \mathrm{K}(\mathrm{min})$ & $54 \mathrm{~W} / \mathrm{m} . \mathrm{K}(\mathrm{min})$ \\
Thermal Expansion & $17.2 \times 10^{-6} / \mathrm{K}$ & $12 \times 10^{-6} / \mathrm{K}$ \\
\hline
\end{tabular}

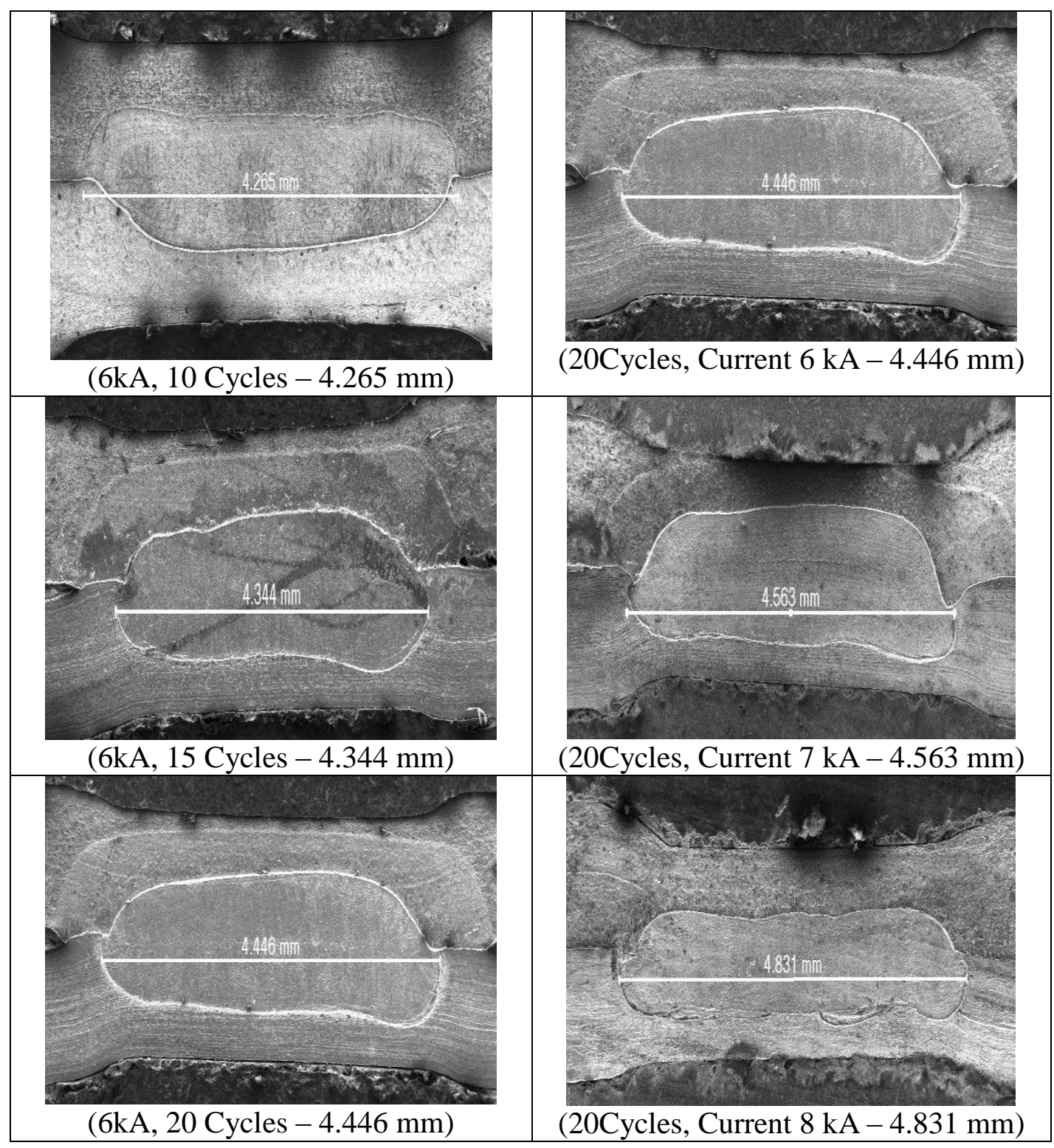

Figure 7. Macrograph of weld nugget with $1 \mathrm{~mm}$ thickness. 


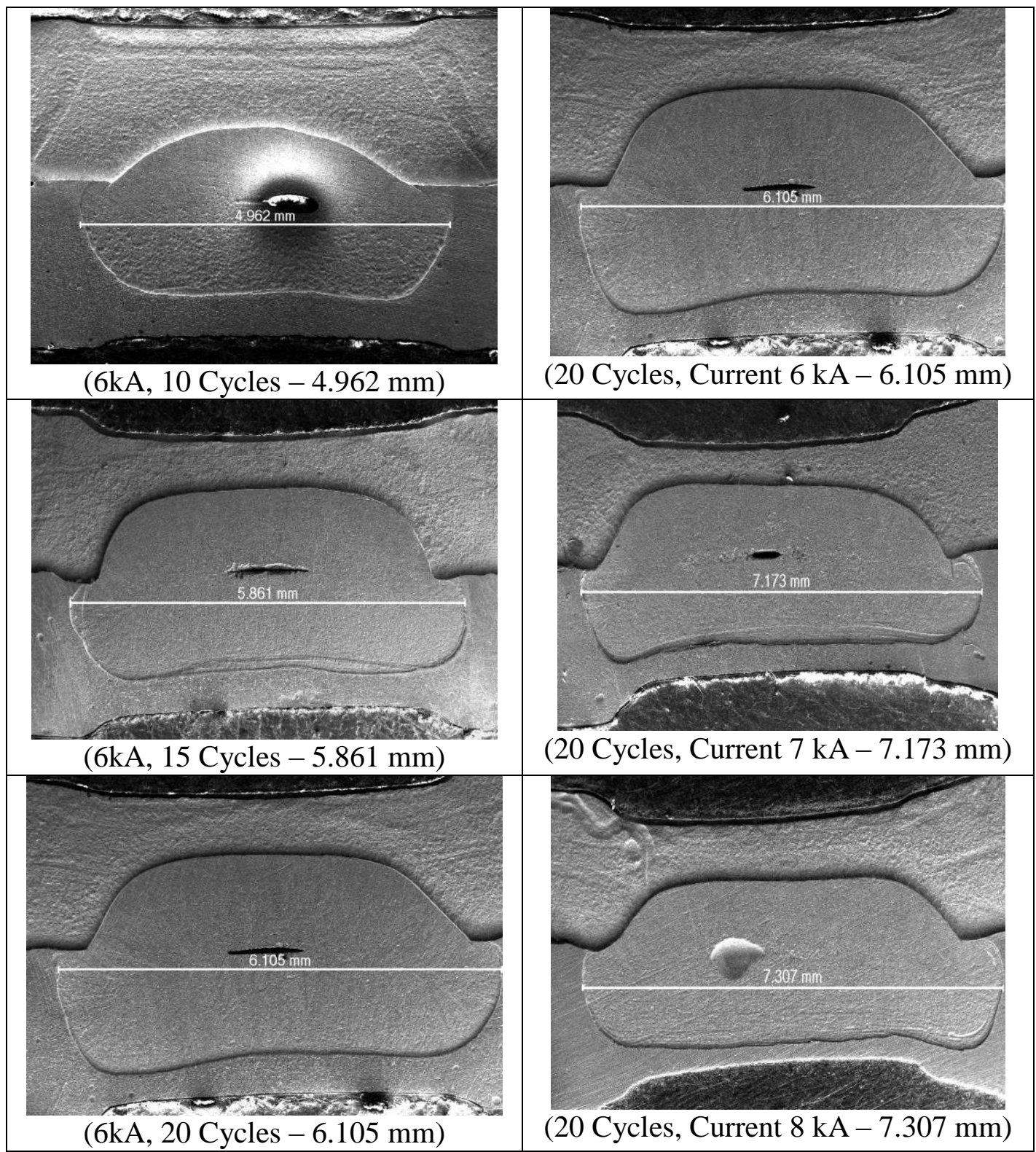

Figure 8. Macrograph of weld nugget with $2 \mathrm{~mm}$ thickness.

\section{CONCLUSIONS}

An analysis of dissimilar spot-welded joints of carbon and stainless steels concluded that:

i) Hardness increments of the welded side (from $55 \mathrm{HRB}$ to $100 \mathrm{HRB}$ and from $75 \mathrm{HRB}$ to $100 \mathrm{HRB}$ ) do exist because of the heat treatment that happens during welding process.

ii) Material thicknesses do not play an important role in hardness increments.

iii) The tensile strength required to break the welded areas is higher for $2 \mathrm{~mm}$ joints compared with $1 \mathrm{~mm}$ joints.

iv) The proportional parametric changes caused proportional increments in tensile strength regardless of material thickness. 
v) Macrographs showed the structural zones of the welded area to determine the weld diameters, as well as asymmetrical nugget growth.

vi) Asymmetrical views of nugget growth demonstrate the heat imbalance due to the different thermal conductivity and different electrical resistivity of the carbon and 304 austenitic stainless steels.

\section{ACKNOWLEDGEMENTS}

I would like to thank the Ministry of Science, Technology and Innovation, Malaysia (MOSTI) for their financial support during the experiment.

\section{REFERENCES}

Cha, B. W., \& Na, S. J. (2003). A study on the relationship between welding conditions and residual stress of resistance. Journal of Manufacturing Systems, 22(3), 181189.

Dursun, O., \& Zyurek. (2008). An effect of weld current and weld atmosphere on the resistance spot weld ability of 304L austenitic stainless steel. Materials and Design, 29(3), 597-603.

Kahraman, N. (2007). The influence of welding parameters on the joint strength of resistance spot-welded titanium sheets. Materials and Design, 28(2), 420-427.

Maa, C., Chena, D. L., Bhole, S. D., Boudreau, G., Lee, A., \& Biro, E. (2008). Microstructure and fracture characteristics of spot-welded DP600 steel. Materials Science and Engineering A, 485(1-2), 334-346.

Marashi, P., Pouranvari, M., Amirabdollahian, S., Abedi, A., \& Goodarzi, M. (2008). Microstructure and failure behavior of dissimilar resistance spot welds between low carbon galvanized and austenitic stainless steels. Materials Science and Engineering A, 420 (1-2), 175-180.

Qiua, R., Satonakab, S., \& Iwamotob, C. (2009). Effect of interfacial reaction layer continuity on the tensile strength of spot welded joints between aluminum alloy and steels. Materials and Design 30(9), 3686-3689.

Shamsul, J. B., \& Hisyam, M. M. (2007). Study of spot welding of austenitic stainless steel type 304. Journal of Applied Sciences Research, 3(11), 1494-1499.

Sun, D. Q., Lang, B., Sun, D. X., \& Li, J. B. (2007). Microstructures and mechanical properties of resistance spot welded magnesium alloy joints. Materials Science and Engineering A, 460-461, 494-498.

von Maubeuge, K. P., \& Ehrenberg, H. (2000). Comparison of peel bond and shear tensile test methods for needle punched geo synthetic clay liners. Geotextiles and Geomembranes, 18(2), 203-214.

Yang, H. G., Zhang, Y. S., Lai, X. M., \& Chen, G. (2008). An experimental investigation on critical specimen sizes of high strength steels DP600 in resistance spot welding. Materials and Design, 29(9), 1679-1684. 